\title{
ALUSÃO EM POEMAS MANUSCRITOS DO HUMANISTA ANTÓNIO DE GOUVEIA
}

\author{
Ricardo dA Cunha Lima \\ Silvia Helena Campanholo
}

Universidade de São Paulo (USP)

\begin{abstract}
Resumo. O humanista português António de Gouveia participou da República das Letras de Lyon, na década de 1530, o período mais importante da produção neolatina do Renascimento francês. Sua obra, na qual predomina o epigrama, baseia-se na imitação dos modelos clássicos. Neste artigo, examinamos trechos de três poemas conservados em manuscritos, identificando e interpretando alusões a autores como Virgílio e Ovídio. Palavras-chave. Alusão, imitatio, Humanismo, epigrama, Virgílio, Ovídio.
\end{abstract}

O humanista António de Gouveia nasceu em Beja, Portugal, por volta de $1510 .{ }^{1}$ Graças a uma bolsa do rei D. João III, outorgada em 1527, realizou seus estudos na França, onde permaneceu a maior parte de sua vida, desenvolvendo uma carreira como filósofo, poeta e professor de Direito. Ligado à vida acadêmica de uma França em pleno desenvolvimento intelectual do Renascimento, mas também em meio aos conflitos religiosos entre católicos e protestantes, Gouveia residiu em diversas cidades, como Paris, Bordeaux, Toulouse, Avignon, Valence e Grenoble. Já famoso como um dos principais professores do direito moderno na Europa, ele faleceu em 1566, em Turim, para onde se deslocara, ao ser contratado para dar aulas na universidade local, que passava por um forte impulso, no momento em que essa cidade substituía Chambéry como capital do Ducado da Saboia.

Uma das cidades por onde o humanista lusitano passou foi Lyon, que, na década de 1530, era uma das capitais do movimento humanista europeu e abrigou alguns dos mais notórios intelectuais da época, como

\footnotetext{
${ }_{1}$ O estudo mais extensivo e, ainda hoje, mais relevante sobre a vida de Gouveia foi realizado pelo egrégio historiador português Joaquim Veríssimo Serrão, que publicou suas conclusões em 1966, na obra António de Gouveia e o seu tempo (1510-1566). Segundo o pesquisador, a hipótese mais plausível para o ano de nascimento de António de Gouveia é 1510, e não 1505, como alguns defenderam e como ainda consta em inúmeros sistemas de dados e catálogos de bibliotecas. As informações aqui apresentadas a respeito da vida de Gouveia foram extraídas dessa obra.
} 
Rabelais, Dolet e Marot, entre inúmeros outros. Gouveia foi admitido no círculo literário da Lyon renascentista e passou a trabalhar com Sébastien Gryphe, um dos mais importantes impressores da Renascença europeia, tornando-se revisor, editor e comentador de obras clássicas, entre as quais as de Cícero, Terêncio e Virgílio. ${ }^{2}$

António de Gouveia permaneceu em Lyon de 1538 a 1541. Em 1539, publicou, pela editora de Gryphe, sua primeira obra poética em latim, intitulada Epigrammaton Libri Duo. No ano seguinte, foi a vez de Epigrammata; eiusdem Epistolae Quattuor. ${ }^{3}$ O conjunto totaliza 157 diferentes epigramas, ${ }^{4}$ além de quatro cartas elegíacas que imitam de perto as Heroides, de Ovídio.

Além desses volumes publicados em vida, são conhecidos 39 poemas de sua autoria, registrados em manuscritos e publicados postumamente, sendo 31 poemas extraídos de um manuscrito conservado na Biblioteca Vaticana e publicados em 1766 por Jakob Van Vaassen; ${ }^{5}$ e oito poemas avulsos, encontrados por Luís de Matos num manuscrito da Biblioteca Nacional da França e publicados em 1952 por esse historiador português. ${ }^{6}$

Existem ainda referências a alguns manuscritos pertencentes a bibliotecas europeias e norte-americanas, rastreados e indicados por Paul Oskar Kristeller em sua obra Iter Italicum, manual de referência dos estudos neolatinos. ${ }^{7}$

Toda a poesia gouveiana foi escrita em latim e inclui epigramas, cartas elegíacas e poemas líricos de extensão variada, compostos sobretudo em dísticos elegíacos e hexâmetros dactílicos.

Assim como ocorre em praticamente todas as composições renascentistas escritas em latim, a intertextualidade, resultante da imitação dos autores da Antiguidade, está inteiramente disseminada na poesia de António de Gouveia. Como declarou Jozef Ijsewijn:

\footnotetext{
${ }^{2}$ Como exemplo de seu trabalho editorial, podemos citar as obras In M. T. Cic. Orationem In Vatinium Commentarius, M. T. Ciceronis Ad M. Brutum Orator, Commentarius in M. T. Ciceronis Topica, In M. T. Ciceronis Libros De Legibus, Pub. Terentii Comoediae Sex e Pub. Vergilii Opera.

${ }^{3}$ Vide bibliografia para referências completas.

${ }^{4}$ Na obra de 1539, Epigrammaton Libri Duo, Gouveia publicou 105 epigramas. Em 1540, na obra Epigrammata, ele publicou mais 100 epigramas. Entretanto, destes cem epigramas, 48 são versões revistas de peças publicadas no ano anterior, e apenas 52 são novos poemas, o que resulta em 157 epigramas efetivamente diferentes.

${ }^{5}$ Vide Antonio de Gouveia, Opera juridica, philologica, philosophica, organizada por Jakob Van Vaassen (Roterdam, 1766).

${ }^{6}$ Vide Matos 1952, 334-47.

7 Vide Kristeller 1963-1997, vol. II, 174, 183, 184; III, 80, 207, 291, 322, 324; IV, 352, 354, 378, 462 , 451; V, 266, 383; VI, 150, 160, 403. No momento, está em elaboração a edição crítica e tradução da poesia neolatina completa de António de Gouveia, a ser publicada pela Imprensa da Universidade de Coimbra, na coleção Portugaliae Monumenta Neolatina.
} 
No author before the age of romanticism ever thought that he or she had to invent everything for the first time. Rather, the choice of a worthy predecessor was the first decision to take; then one could and would try to do even better. The numerous treatises De imitatione show the overriding importance of the principle for humanist literature. ${ }^{8}$

Assumindo a afirmação de Paulo Sérgio de Vasconcellos, de que "os antigos Romanos sempre tiveram consciência de que sua literatura era, na quase totalidade, literatura de 'segundo grau'", , podemos dizer que a literatura neolatina, nessa acepção, é uma literatura de terceiro grau.

Diante disso, a identificação e interpretação das alusões é essencial para uma compreensão mais aprofundada da poesia neolatina, incluindo aí a obra de Gouveia. Tal investigação, com efeito, é um dos passos primordiais na abordagem dessa literatura, enriquecendo a análise da obra desse humanista português e revelando como Gouveia se servia da imitação e quais efeitos ele conseguia alcançar.

Como base metodológica de investigação da intertextualidade resultante dos procedimentos alusivos, seguimos uma concepção já tradicional de alusão, apoiada em textos como os de Giorgio Pasquali ("Arte Allusiva") ou D. A. Russell ("De imitatione"), ${ }^{10}$ que reconhecem a imitatio como uma característica intrínseca da literatura clássica e a alusão como uma manifestação intencional de imitatio. Entretanto, apesar de reconhecermos a alusão como um recurso evidente e proposital de um autor, nossa investigação evita a embaraçosa problemática de tentar descobrir qual seria "exatamente" o propósito do poeta. Uma vez identificada a alusão, apenas propomos possíveis efeitos de sentido resultantes da aproximação intertextual, nas pegadas de pesquisadores como Barchiesi, Conte, Hinds, Vasconcellos ou Patrícia Prata, entre tantos outros, que trabalham sob a perspectiva, por exemplo, da multiplicidade de interpretações, abertas e instáveis - resultantes da aproximação de textos ou de arquétipos genéricos -, ou ainda da influência dos textos modernos sobre seus modelos, numa dinâmica de mão dupla da intertextualidade.11

Nessa linha de pesquisa, analisaremos três poemas manuscritos de António de Gouveia. Trata-se de textos nunca antes traduzidos, analisados ou interpretados. Procuramos selecionar, nos poemas, passagens cuja lei-

${ }^{8}$ Ijsewijn \& Sacré 1998, 412.

${ }^{9}$ Vasconcellos 2001, 13.

${ }^{10}$ Vide bibliografia para referência completa.

${ }^{11}$ A pesquisadora Patrícia Prata, em capítulos iniciais de sua dissertação de mestrado e de sua tese de doutorado, apresenta um panorama esclarecedor dos estudos de intertextualidade aplicados no ambiente dos Estudos Clássicos, de muito proveito para serem utilizados também nos estudos da estilística renascentista. Cabe salientar ainda o trabalho desenvolvido pelo grupo de pesquisa "Intertextualidade na literatura latina", sediado na Unicamp. 
tura, instrumentalizada pela percepção da intertextualidade, ganha alternativas de sentido, muitas vezes esclarecedoras ou amplificadoras. De fato, os poemas conservados em manuscritos revelam as mesmas características de composição segundo a arte alusiva que encontramos nos demais textos gouveianos, que fazem com que sua obra, no todo, esteja intimamente ligada à literatura antiga, devido aos procedimentos de imitação e emulação que a caracterizam na sua essência.

O primeiro poema a ser analisado faz parte do conjunto de poemas publicados postumamente, em 1766, por Jakob Van Vaassen, a partir de um manuscrito encontrado na Biblioteca Vaticana. ${ }^{12} \mathrm{O}$ conjunto, intitulado Carmina pelo estudioso holandês, contém 31 poemas, entre os quais predomina o epigrama fúnebre, com 13 peças. Sendo assim, começaremos pelo exame de um desses epigramas sepulcrais, o poema 24, feito em homenagem ao rei Henrique II, da dinastia dos Valois, falecido em 10 de julho de 1559.

\section{M. HENRICI VALESII FRANCORVM REGIS}

Vicerat, et uicto pacem concesserat hosti:

Imperii late fines promouerat: orbem

Implebatque suum, fatis cum cessit iniquis.

Prisca fides, pietasque, inuictaque dextera bello

Visa potens nimium, superi, res Gallica uobis

Henrico permissa diu si sceptra fuissent.

\section{EM MEMÓRIA DO REI FRANCÊS HENRIQUE DE VALOIS}

Ele venceu, e concedeu a paz ao inimigo vencido;

Estendeu amplamente as fronteiras do império;

E concluía o território de seu país, quando, por fados injustos, caiu.

A tradicional lealdade, e a devoção, e a mão direita invicta na guerra!

A nação francesa vos pareceria excessivamente poderosa, ó deuses,

Se a coroa tivesse sido confiada por mais tempo a Henrique..$^{13}$

Os três versos finais do epigrama foram moldados a partir de uma famosa passagem do sexto canto da Eneida, entre os versos 860 e 886, em que Virgílio canta a morte de Marcelo, sobrinho de Augusto e tido como seu provável herdeiro. Augusto indicou sua preferência por Marcelo ao dar-lhe em casamento sua filha única, Júlia, em 25 a.C. Mas, em 23 a.C., Marcelo faleceu prematuramente, aos 19 anos, para dissabor e tristeza de Augusto. Essa

${ }_{12}$ Ms. 1491 do Fondo Reginense Latino, Biblioteca Apostolica Vaticana.

${ }_{13}$ Tradução de Ricardo da Cunha Lima. Doravante, todas as traduções serão de Ricardo da Cunha Lima, salvo quando houver indicação em contrário. 
morte trágica, poeticamente retratada por Virgílio, também foi cantada por Propércio, na elegia 3.18. No trecho da Eneida, Anquises, questionado por Eneias - que deseja saber quem é um belo rapaz que circula no mundo dos mortos -, explica ao filho que se trata da maior esperança de glória entre os romanos, um jovem guerreiro que, em razão da morte prematura, serve de exemplo do grande sofrimento (ingentem luctum) pelo qual passará o povo de Roma. As características da morte prematura de Marcelo, num contexto claramente relacionável com a essência do epigrama sepulcral, dão oportunidade a que Gouveia associe esses elementos às circunstâncias semelhantes da biografia de Henrique II, que morreu tola e inesperadamente aos quarenta anos, em razão de ferimentos causados num duelo de torneio, após doze anos de reinado. O humanista português imita não apenas o teor do poema e as palavras da composição, mas também a atitude de Virgílio, que usou a poesia para louvar o príncipe e celebrar a autoridade política. Para tramar essa aproximação, Gouveia faz alusão a quatro versos do sexto canto da Eneida (870-1 e 878-9), citados a seguir:

[...] nimium uobis Romana propago

uisa potens, superi, propria haec si dona fuissent.

$[\ldots]$

heu pietas, heu prisca fides inuictaque bello

dextera!

Isolemos o quarto verso do poema gouveiano:

Prisca fides, pietasque, inuictaque dextera bello ${ }^{14}$

Apesar de algumas inversões na ordem, temos praticamente as mesmas palavras de Virgílio, exceto pela supressão da interjeição de lamento heu, duas vezes usada pelo mantuano. Fazendo isso, o português aplica a Henrique II as mesmas palavras que Anquises usa para descrever o magnífico Marcelo. Pela alusão, Gouveia faz coincidir as duas figuras, atribuindo a Henrique II a mesma importância e o mesmo destino que a Antiguidade clássica atribuía ao promissor líder romano. Note-se que Henrique II cumpre, nos primeiros versos do poema renascentista, exatamente a mesma função que Virgílio atribui aos romanos, na Eneida (6.851-3): impor o império e oferecer paz aos povos submetidos. ${ }^{15}$

Essa assimilação também é reforçada no final do poema: assim como Henrique II é um novo Marcelo, a França é a nova Roma. Gouveia faz isso

${ }^{14}$ Grifamos as palavras retiradas de Virgílio.

${ }_{15}^{15}$ Trata-se, aqui, de uma paráfrase, a partir do original latino. 
ao utilizar, na descrição da França, as mesmas palavras de Virgílio acerca de Roma. Tornemos a ver, com efeito, os versos de Gouveia, agora em comparação com os do mantuano:

Visa potens nimium, superi, res Gallica uobis

Henrico permissa diu si sceptra fuissent. ${ }^{16}$

Como no exemplo anterior, há uma série de inversões, mas as palavras são as mesmas, com exceção de uma substituição fundamental: Romana propago ("raça romana") se torna res Gallica ("nação francesa"). Dessa forma, igualam-se as duas nações, e a França passa a ser, pela arte alusiva, a herdeira e sucedânea de Roma, o que, aliás, tem uma importância capital se pensarmos nos interesses e nos conflitos geopolíticos da época. De fato, o grande rival de Henrique II e do poder dos Valois foi Carlos V, da casa dos Habsburgos, que se fazia reconhecer como imperador do Sacro Império Romano-Germânico, ou, simplesmente, Sacrum Imperium Romanum. Assim, transferir simbolicamente o território e, consequentemente, o título de imperador romano, dos Habsburgos, para Henrique II, tem um altíssimo valor, ainda mais num epitáfio laudatório.

Pelas observações, podemos notar, com esse primeiro exemplo, como a poesia renascentista de António de Gouveia está imbuída da imitação dos antigos que rege a composição clássica e como a identificação das alusões e a interpretação plausível das aproximações entre os textos é relevante e ajuda a iluminar a obra moderna com novos significados.

Passemos agora ao poema "Adônis", que abre a coletânea de 31 poemas do já mencionado manuscrito Vaticano e que pode ser considerado um dos mais belos da poesia gouveiana. Esse poema de 112 versos narra uma versão do conhecido mito de Adônis e pode ser dividido em quatro partes: a primeira, em que Vênus recebe a notícia da morte iminente de seu amado, atacado por um javali; a segunda, na qual a deusa, a natureza e os animais lamentam a morte de Adônis; a terceira, em que ela vai ao encontro do jovem, que morre em seus braços; e uma última parte, na qual Vênus pede que o javali assassino sofra inúmeros suplícios.

No poema há várias alusões a poetas clássicos, como Ovídio e Virgílio. Algumas dessas alusões serão apresentadas e comentadas na ordem em que aparecem no poema de Gouveia. A primeira delas está presente nos versos 7-9 do poema, em que a voz de um núncio se dirige a Vênus e se refere ao carro divino:

${ }^{16}$ Grifamos as palavras retiradas de Virgílio. 
Pro molli uiola, pro purpureo narcisso,

Pro myrto et grati ueris honore rosa,

Funerea intendat currum tibi fronde cupressus...

Em lugar da terna violeta, do purpúreo narciso,

Da murta e da rosa em celebração da agradável primavera,

Que tua carruagem se cubra com a folhagem do fúnebre cipreste...

O primeiro verso desse trecho foi incorporado inteiro, sem modificação, da écloga 5 de Virgílio. Essa écloga, segundo Alexandre Hasegawa, está no centro das Bucólicas de Virgílio. ${ }^{17}$ A personagem principal é Dáfnis, "o inventor do canto bucólico, o boiadeiro modelar e a própria encarnação do gênero". ${ }^{18}$ Nela encontramos Menalcas e Mopso, dois poetas pastores, celebrando Dáfnis. Mopso canta sua morte e Menalcas sua deificação. O verso que Gouveia incorporou de Virgílio se refere ao momento em que Mopso canta a morte de Dáfnis. São os versos 38-39:

Pro molli viola, pro purpureo narcisso,

Carduus et spinis surgit paliurus acutis.

Em lugar da terna violeta, do purpúreo narciso,

Surgem o cardo e o paliúro de espinhos agudos.

Segundo Hasegawa, "no canto de Mopso, os deuses e, sobretudo, as ninfas lamentaram a morte de Dáfnis". ${ }^{19} \mathrm{O}$ mesmo ocorre no poema de Gouveia, pois não foi apenas a deusa Vênus que lamentou a morte de Adônis: no verso quarenta, Gouveia diz "flebiliter miserae congemuere Deae" ("gemeram dolorosamente as deusas infelizes").

O verso que Gouveia incorporou de Virgílio apresenta a mesma imagem de sua écloga: flores delicadas sendo substituídas por plantas espinhosas e agrestes, que lembram o sofrimento e a morte. Desse modo, não são apenas as ninfas e Vênus que lamentam a morte de Dáfnis e Adônis, mas a natureza também sofre com essas mortes e, para demonstrar esse sofrimento, se transforma em plantas espinhosas.

Ainda de acordo com Hasegawa, a écloga 5 de Virgílio estabelece algumas relações com o canto de Tírsis no idílio 1 de Teócrito. Com efeito, nesse idílio a natureza exprime um desejo de se tornar rude e feia, desejo que, de certa forma, se concretiza nos textos de Virgílio e Gouveia, nos quais a natureza se traveste de dor. Como adendo, cabe informar que Gou-

${ }_{17}$ Hasegawa 2012, 149.

${ }_{18}$ Idem, ibidem.

19 Idem, 159. 
veia conhecia a obra desse autor grego e chegou a verter o idílio 19 para o latim, em duas diferentes versões. ${ }^{20}$

Agora passemos a um trecho do poema "Adônis" em que há, ao mesmo tempo, uma alusão a Ovídio e Virgílio. São os versos 14-18, nos quais se expressa a reação dolorosa da deusa Vênus, ao saber da tragédia:

Exanimis uiridi procubuitque solo:

Et ter se subito conata attollere, rursum

Liquitur, et cubito deficiente cadit.

Atque ubi mortiferi spatio uis uicta doloris,

Aegraque de gelida membra leuauit humo

E tombou, sem vida, no verde chão:

Por três vezes ela tentou erguer-se, mas, repetidamente,

Ela desaba e, sem força nos braços, cai.

Então, quando o impacto da dor foi superado, após um intervalo mortificante,

Levantou os membros abatidos da terra fria

Apontemos, primeiramente, a alusão referente a Ovídio, que se encontra no primeiro e no último versos desse trecho e que partiu do primeiro livro dos Tristes, poema 3. Nesse poema, Ovídio narra sua última noite em Roma antes do exílio e o modo como sua esposa ficou desesperada com sua partida. É o que podemos verificar nos versos 91-94:

Illa dolore amens tenebris narratur obortis

Semianimis media procubuisse domo,

Vtque resurrexit foedatis puluere turpi

Crinibus et gelida membra leuauit humo

Contam que perdeu os sentidos por causa da dor,

Tombando semimorta no meio da casa,

E que, quando se reanimou, levantou os membros do chão gelado,

Tendo os cabelos sujos pela poeira imunda ${ }^{21}$

Reapresentemos os versos de Gouveia:

Exanimis uiridi procubuitque solo:

$[\ldots]$

Aegraque de gelida membra leuauit $\underline{\text { humo }}^{22}$

${ }^{20}$ Durante a Renascença, o idílio 19 era considerado autêntico.

${ }^{21}$ Tradução de Prata 2002, modificada.

${ }^{22}$ Grifamos as palavras retiradas de Ovídio. 
Como pode ser notado, a maior parte do verso 97 foi imitado sem modificação (gelida membra leuauit humo). Quanto ao verso 95, há algumas variações: em Ovídio temos o verbo procubuisse no infinitivo pretérito e em Gouveia o pretérito perfeito, e a partícula que se acoplou ao verbo. Entre semianimis e exanimis, Gouveia substituiu o prefixo, o que confere maior expressividade ao seu verso, pois o prefixo ex é mais forte do que semi. Ao fazer isso, Gouveia obtém o efeito de deixar Vênus mais prostrada que a esposa de Ovídio, pois o amado de Vênus morreu e não voltará mais, enquanto Ovídio estava indo para o exílio e, naquele momento, haveria a possibilidade de seu retorno. Assim, fica clara a importância da identificação da fonte onde Gouveia foi buscar inspiração. Essa identificação traz maior significado ao desfalecimento de Vênus, ao saber da morte iminente de Adônis.

Vejamos a alusão, do mesmo trecho, que remete a Virgílio, Eneida 4.690-1:

Ter sese attollens cubitoque adnixa leuauit

Ter revoluta toro est...

Por três vezes ela se ergue, apoiando-se nos cotovelos,

Por três vezes ela torna a cair sobre o leito...

Vejamos comparativamente os versos de Gouveia:

Et ter se subito conata attollere, rursum

Liquitur, et cubito deficiente cadit. ${ }^{23}$

Os versos da Eneida se inserem no momento em que Dido, sofrendo com a partida de Eneias, se fere e está agonizando. Então, sua irmã chega e ainda tenta chamá-la de volta para a vida. Como podemos observar, Gouveia imita algumas palavras do verso de Virgílio: a palavra ter continua do mesmo modo; já a partícula sese perde sua intensidade em Gouveia, pois ele utiliza apenas $s e$; o verbo attollens passou do particípio presente para o infinitivo; a palavra cubitoque foi passada para o verso posterior e a partícula que se desmembrou de cubito. Notamos que Virgílio utilizou o verbo reuoluo na voz passiva, significando cair, e que Gouveia utilizou cado com o mesmo sentido. Assim, a imagem de Dido alguns segundos antes de morrer intensifica o sofrimento de Vênus, revelando o quanto ela sofreu ao saber da morte iminente de Adônis. É importante notar que Vênus, no poema "Adônis", também desejou morrer, mas, devido à sua condição de deusa, isso era impossível.

${ }^{23}$ Grifamos as palavras retiradas de Virgílio. 
No próximo trecho, podemos observar que há no poema "Adônis" outra alusão à já mencionada écloga 5 de Virgílio. Nos versos 43-46 de Gouveia temos:

Et silua ex omni gemuere armenta: nec illo

Aut herbam quadrupes attigit ulla die:

Aut liquidas libauit aquas, aut ubera natis

Plena dedit, tecto supposuitue caput.

Também, de toda a floresta, gemeram as manadas. Naquele dia,

Nenhuma rês tocou no capim,

Nem bebeu de águas limpidas, nem ofereceu os úberes

Cheios às crias, ou procurou abrigo.

E nos versos 24-28 da écloga 5 temos:

non ulli pastos illis egere diebus

frigida, Daphni, boves ad flumina; nulla neque amnem

libavit quadrupes nec graminis attigit herbam.

Daphni, tuum Poenos etiam ingemuisse leones

interitum montesque feri silvaeque loquuntur.

Naqueles dias, ninguém levou os bois, que pastaram, aos frescos

Rios, Dáfnis; nenhuma rês

Bebeu água nem tocou a erva da relva.

Dáfnis, os feros montes e os bosques

contam que até os leões púnicos gemeram por tua morte. ${ }^{24}$

Essa imitação incorpora sete palavras. O verbo ingemuisse de Virgílio passou, mais uma vez, do infinitivo passado para a terceira pessoa do plural do pretérito perfeito em Gouveia e, ao ser apropriado, perdeu seu prefixo in. Já as palavras quadrupes, attigit e herbam foram trocadas de posição; além disso, nec ficou no verso anterior e libauit no verso posterior. Em Virgílio temos diebus e em Gouveia die: o substantivo passou do ablativo plural para o singular. Tal alusão é construída por meio das palavras e do assunto, pois nas duas composições os animais chegam a chorar pela morte de Dáfnis/ Adônis, ficam prostrados, não bebem água e não comem.

Essa imagem dos animais chorando já estava presente em Teócrito, de acordo com Hasegawa: "tanto em Mopso quanto em Tírsis, os animais ferozes deploram a morte do filho de Mercúrio". ${ }^{25}$ Como podemos verificar nos versos 71-72 do idílio 1 de Teócrito:

24 Tradução de Hasegawa 2012, modificada.

${ }^{25}$ Idem, 176. 


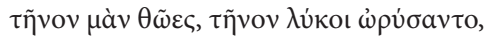

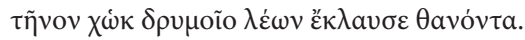

Por ele, decerto, os chacais uivaram; por ele, os lobos uivaram;

Por ele, que morria, o leão da floresta também chorou. ${ }^{26}$

Ainda segundo Hasegawa, Virgílio e Teócrito queriam mostrar "como o mundo todo - divino, humano e animal - lamenta o herói bucólico". ${ }^{27}$ Desse modo, vemos como é significativa essa imagem dos animais chorando e como ela ganha significado ao pensarmos na écloga 5 e no idílio 1 .

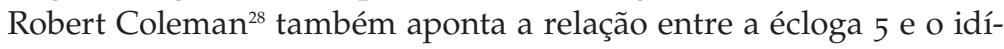
lio 1 de Teócrito e ainda acrescenta que a imagem dos animais chorando pela morte de Dáfnis pode ser uma referência à Ilíada de Homero, canto 17 , que narra o momento da luta entre Menelau e Heitor pelo corpo do jovem Pátroclo. A discussão entre eles resulta numa batalha entre seus exércitos. Os versos que nos interessam são os 426-428:

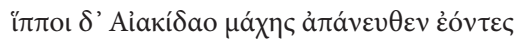

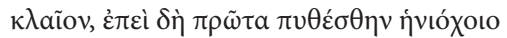

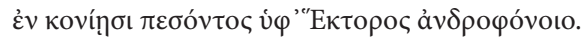

À margem da batalha, os cavalos de Aquiles

Choravam, contemplando arrojado no pó

Seu condutor, pela mão de Héctor, homicida. ${ }^{29}$

Fica claro que o ambiente em que se dá a poesia épica é diferente do ambiente das éclogas. Devido a isso, Virgílio e Gouveia utilizaram quadrupes para se referir aos animais e não equus, que seria o equivalente latino da palavra grega ï $\pi$ ro. Na écloga de Virgílio e no poema de Gouveia, a tradução da palavra quadrupes deve ser rês e não cavalo. Assim, vemos que a obra de Gouveia, mais uma vez, cria um efeito de sentido com a literatura latina e com a literatura grega, lembrando, como dito acima, que Gouveia traduziu o idílio 19 de Teócrito.

Outra alusão está presente nos versos 55-58 de Gouveia:

Sed necis in solam confert scelus omne Dianam,

Ingenium multis mitius esse feris:

Et quibus ipsa bonis caret, obtrectare maligne,

Quae si nec Virgo nec scelera foret.

\footnotetext{
26 Tradução de Hasegawa 2012.

${ }^{27}$ Idem, 179.

28 Coleman 2001.

29 Tradução de Campos 2004.
} 
Mas atribui todo o crime do assassinato somente a Diana, afirmando:

Muitas feras selvagens têm uma indole mais afável,

Ao passo que ela ataca maldosamente as qualidades que não possui,

Como se não fosse nem virgem nem criminosa.

Nesse trecho nos deparamos com Vênus acusando Diana pela morte de Adônis. Os versos apresentam maior expressividade se pensarmos na obra Amores de Ovídio (10.25-28):

Sumite in exemplum pecudes ratione carentes;

turpe erit, ingenium mitius esse feris.

Non equa munus equum, non taurum uacca poposcit,

Non aries placitam munere captat ouem.

Tomai como exemplo os animais sem razão:

será uma vergonha que as feras selvagens tenham uma índole mais afável.

A égua ao cavalo e a vaca ao touro regalos não pedem,

O carneiro não conquista com regalos a ovelha que lhe agrada. ${ }^{30}$

No verso 21 dessa elegia, Ovídio chama sua puella de meretriz, levando-nos a crer que ela tem um caráter duvidoso: stat meretrix certo cuiuis mercabilis aere, "de pé está a meretriz, por qualquer um comprável a preço certo." Segundo Lucy Ana de Bem "a menina requer presentes e, se ele não os der, um outro dará". ${ }^{31}$ Na passagem que nos interessa, Ovídio chega a dizer que se a puella não parar de pedir esses presentes, até mesmo as feras selvagens terão um caráter melhor que o seu, pois elas não pedem nada em troca do amor. Gouveia imitou quase todo o verso 56 de Ovídio e não mudou a ordem das palavras no verso, inserindo apenas a palavra multis. A partir da alusão mostrada acima, podemos fazer uma analogia entre Diana e a meretriz de Ovídio, pois Vênus ataca o orgulho da deusa virgem usando a expressão nec uirgo. Assim, se essa expressão for repensada a partir da elegia 10 de Ovídio, seu sentido se ampliará ainda mais, pois Diana não é apenas nec uirgo, ela também chega a ser uma meretrix.

Passemos agora a mais uma imitação que Gouveia fez da Eneida de Virgílio. Os versos em que o poeta inseriu a imitação retratam Vênus lamentando o destino cruel de Adônis e reclamando que eles pertencem a mundos diferentes, o que a leva a indagar, nos versos $65-66$ :

Sed, miserande puer, qui te furor impulit alta

Per nemora immites exagitare feras?

30 Tradução de Bem 2007, modificada.

${ }_{31}$ Bem 2007, 209. 
Mas, jovem miserável, que loucura te impeliu pelos bosques elevados A caçar feras atrozes?

A expressão miserande puer está presente em três cantos da Eneida de Virgílio. O primeiro canto em que a expressão aparece é o sexto, que narra a descida de Eneias ao Hades, para encontrar seu pai. Trata-se do mesmo trecho já comentado acima, em que Anquises lamenta a morte prematura de Marcelo. Anquises se refere a ele deste modo, versos 882-3:

Heu, miserande puer, si qua fata aspera rumpas!

Tu Marcellus eris!

Ai, jovem miserável, quem dera pudesses vencer os duros fados!

Tu serás Marcelo! ${ }^{32}$

A próxima ocorrência da expressão miserande puer está no canto dez, onde é narrada a luta entre troianos e latinos. Quando Eneias está prestes a dar o golpe de misericórdia em Mezêncio, seu filho Lauso se interpõe entre ambos, refreando o golpe, e, após alguns instantes de luta, Eneias termina por matá-lo. No entanto, ao ver que Lauso morria, Eneias se lembra de seu próprio filho e se compadece do jovem, dizendo-lhe estas palavras, versos 825-6:

quid tibi nunc, miserande puer, pro laudibus istis,

Quid pius Aeneas tanta dabit indole dignum?

E agora, jovem miserável, o que te dará, em face de teus méritos,

O que te dará o pio Eneias que seja digno de tamanha coragem?

A terceira ocorrência de miserande puer se encontra no início do canto onze. Nele Eneias e seus companheiros prestam honras a seus mortos. Um deles é o escudeiro Palante. Eneias se mostra muito abalado com a morte de Palante e chega a chorar. Ele também sente pela dor de Evandro, que ficará sem seu filho. Então ele dirige as seguintes palavras ao cadáver do jovem Palante, versos 42-44:

Tene, inquit, miserande puer, cum laeta veniret, Invidit Fortuna mihi, ne regna videres

Nostra neque ad sedes victor veherere paternas?

Foi a ti, jovem miserável, que a Fortuna, num momento feliz, Escolheu prejudicar, por inveja de mim, impedindo que visses Meu reinado e que chegasses como vitorioso à casa paterna?

${ }^{32}$ Na tradução, foi seguida a análise de Austin 1988, que alerta para o valor desiderativo do verso 882 (si qua fata aspera rumpas). 
Assim, podemos ver que nos três trechos se expressa um sentimento de luto, observa-se uma tomada de consciência a respeito da morte de jovens que falecem na condição de heróis, tendo sua valentia admirada. Nesse contexto, é lapidar o vocativo miserande puer, isto é, "jovem digno de ser lamentado, de ser chorado". Embora somente os dois últimos fragmentos de Virgílio falem de mortes violentas em batalha - uma vez que Marcelo morreu vítima de uma doença, durante seu pretorado em Baia -, as três passagens constroem um ambiente bélico, de exaltação da coragem guerreira. No poema renascentista, apesar da mudança de ambiente, Gouveia atribuiu a Adônis a expressão miserande puer, enobrecendo sua morte violenta e cruel. Assim, apesar de estarmos em um contexto bucólico, a expressão que Vênus utiliza para se referir a Adônis confere-lhe um caráter de herói épico.

Vejamos agora outra alusão que cria um efeito de sentido com a Eneida. Há na poesia clássica a expressão terque quaterque, imitada por Gouveia. Ela aparece quatro vezes em Virgílio, cinco vezes em Ovídio e seis vezes em Marcial. Diante de tamanho número de ocorrências, fica claro o caráter formular de terque quaterque. No entanto, se ampliarmos o excerto e procurarmos essa expressão acrescida da palavra manu, como no verso 90 de Gouveia (cum ferro adducta terque quaterque $\underline{\text { manu }}^{33}$ ), podemos encontrá-la em dois momentos da Eneida de Virgílio. Na Eneida 4.589 temos:

Terque quaterque manu pectus percussa decorum

Três, quatro vezes golpeando o peito formoso ${ }^{34}$

E no canto doze da Eneida, verso 155:

Terque quaterque manu pectus percussit honestum.

Três, quatro vezes golpeou o belo peito.

Como podemos ver nesses trechos da Eneida, o próprio Virgílio se imita. No quarto canto, presenciamos a partida de Eneias e a dor de Dido diante do abandono, que culmina em sua morte. No canto doze nos deparamos com o momento em que Juturna recebe a notícia de que seu irmão irá morrer. E o verso de Gouveia mostra quando Vênus expressa o desejo de que o javali assassino tenha seu dente arrancado várias vezes, à maneira de uma punição. Logo, percebe-se que a palavra manu é usada para praticar ações diferentes: em Gouveia a mão arranca os dentes e em Virgílio a mão bate no peito em sinal de luto. Além disso, a expressão aparece na primeira parte do verso de

\footnotetext{
33 "Arrancado por uma mão armada com ferro, três, quatro vezes".

34 Tradução de Nunes 1981, modificada.
} 
Virgílio e, em Gouveia, ela se posiciona como a última parte do verso, como se o humanista português intencionalmente representasse, por meio da disposição invertida das palavras, a inversão efetuada no sentido da frase. Se pensarmos nas ações que estão sendo praticadas, aparentemente é mais a fórmula que está sendo imitada do que sua função propriamente dita, pois, como acabamos de falar, no trecho de Gouveia a mão arranca os dentes e não bate no peito como em Virgílio. No entanto, podemos notar que o ambiente em que se insere a expressão, nos três fragmentos, diz respeito a uma perda. Nos dois fragmentos da Eneida e no poema "Adônis", verificamos que as três mulheres quiseram morrer por causa da perda de uma pessoa que lhes era muito cara. No entanto, a única que realmente alcança a morte é Dido, pois ela era mortal. Já Vênus e Juturna, pelo fato de serem respectivamente deusa e ninfa (o próprio Carlos Alberto Nunes utiliza a expressão "ninfa Juturna" em vários momentos de sua tradução) não puderam morrer, mas as duas desejaram isso. É interessante pensar na relação que se estabelece entre Dido, Juturna e Vênus: as três partilham do mesmo sofrimento.

Concluindo as análises acerca de "Adônis", novamente observamos uma forte presença clássica na poesia de António de Gouveia, cuja interpretação pode ser enriquecida e ganhar novos sentidos com o estabelecimento de análises intertextuais. Nesse poema, notamos que quase todas as imitações feitas por Gouveia partiram de trechos da literatura clássica em que há ambientes de perda. A única alusão onde isso não ocorre é aquela que estabelece efeito de sentido com a obra Amores de Ovídio, uma vez que o trecho do poema de Gouveia em que se insere a alusão não faz mais parte do momento de dor e lamento, e sim do momento em que Vênus procura um culpado pelo assassinato de Adônis e deseja que o javali sofra inúmeros suplícios.

Para encerrar, examinaremos um poema pouquíssimo conhecido: uma écloga de 167 versos, que faz parte de um conjunto de oito poemas publicados pelo historiador Luís de Matos, em 1952, em sua obra Les Portugais en France au XVIe siècle: études et documents, da Universidade de Coimbra. Os poemas fazem parte do manuscrito 8179 da Biblioteca Nacional de Paris.

A écloga é, na verdade, uma versão relativamente livre de um canto pastoral (chant pastoral) de Pierre de Ronsard, um dos mais proeminentes escritores do século xvi e líder da chamada Plêiade de poetas.

O título do poema francês é «Eclogue iII ou Chant Pastoral sur les Noces de Monseigneur Charles, Duc de Lorraine, et Madame Claude, deuxième fille du Roi Henry II ». O poema celebra as núpcias do Duque de Lorena com a Princesa Cláudia, filha do rei Henrique II, mencionado no epigrama fúnebre acima comentado. O casamento ocorreu no mesmo ano da morte do rei, em 1559, no Castelo de Meudon, de propriedade do tio do noivo, 
o Cardeal de Lorena e de Guise, Charles de Lorraine, ${ }^{35}$ que havia mandado erigir nos jardins do palácio uma gruta dedicada às ninfas e às musas. É curioso que a postura católica intransigente do cardeal, um dos líderes da Contra-Reforma na França e perseguidor contumaz dos protestantes, não o impediu de montar em seu castelo uma gruta artificial de inspiração clássica, plena de referências "pagãs", espaço de culto às musas, às ninfas e a Pã, como se depreende dos poemas que a celebram e das informações históricas acerca da construção, cujo projeto ficou a cargo do arquiteto e escultor italiano Francesco Primaticcio, conhecido na França como Le Primatice.

O poema de Ronsard é claramente moldado nos modelos clássicos e sobretudo na poesia bucólica de Virgílio. O interessante é que Gouveia, ao verter o poema para o latim, latiniza ainda mais o texto, utilizando expressões e versos extraídos de autores da Antiguidade. Antes de examinarmos algumas passagens, cabe notar que Gouveia não verte o poema inteiro, mas se concentra apenas na parte inicial, que descreve a gruta artificial erigida por Carlos de Lorena. Nesse sentido, o título da composição do lusitano é Antrum Maedonium ab Antonio Goueano ex Gallicis Ronsardi expressum, isto é, "A gruta de Meudon, composição de António de Gouveia a partir dos versos em francês de Ronsard". Aliás, o título do poema já serve de exemplo da latinização do texto: Gouveia não apenas cria o adjetivo Maedonius, latinizando à sua maneira o topônimo Meudon; mas, no verso 57, inventa as Musae Maedonides ("Musas Medônides"), no melhor esquema clássico, e ainda brinca, afirmando: gaudent iam nomine, ou seja, elas (as musas) já estão gostando do nome (recém-forjado).

Decerto, se Gouveia desejava latinizar a versão classicista de Ronsard, esperaríamos que recorresse com alguma frequência a versos bucólicos de Virgílio. É o que veremos nos dois primeiros exemplos. Assim, no verso 75, ele escreve, ao elogiar Carlos de Lorena:

Carole, semper eris nobis Deus

Carlos, sempre serás um deus para nós

É evidente a alusão ao início da primeira écloga virgiliana, especialmente o sétimo verso:

namque erit ille mihi semper deus

Por isso, ele será sempre um deus para mimº

${ }^{35}$ Doravante adotaremos o nome aportuguesado, Carlos de Lorena.

36 Tradução de Zélia de Almeida Cardoso, in Novak 2003. 
O curioso é que o verso original, em Ronsard, é:

Car c'est un demi-Dieu, à qui plaisent nos sons

Pois é um semideus a quem agradam nossos sons

Aparentemente, Ronsard também se inspira em Virgílio, mas, talvez por uma exigência do decoro da época, preferiu a fórmula demi-Dieu ("semideus") ao dirigir-se ao cardeal. Mas Gouveia não perde a oportunidade de associar a passagem ao célebre início das Bucólicas, e aproveita a expressão virgiliana, convertendo demi-Dieu em Deus e, dessa forma, tornando o poema ainda mais arcaizante que sua expressão original. Algo semelhante ocorre no verso 141 de Gouveia:

Siluestris totam spargat labrusca racemis

Que a labrusca silvestre a cubra por inteiro com seus racimos.

Trata-se de alusão ao verso 7 da écloga 5 de Virgílio:

Siluestris raris sparsit labrusca racemis

A labrusca silvestre cobriu com raros racimos ${ }^{37}$

Nas duas passagens, temos a descrição de uma gruta, a ser tomada pelo vinhedo silvestre, simbolizando a presença do vinho e, conforme nos indica Alexandre Hasegawa, seguindo sugestão de Tomislav Deur, igualmente de Baco. ${ }^{38}$ Comparemos com o original francês, de Ronsard:

Et la lambrunche errante, ensemble entortillée ${ }^{39}$

Laisse espandre ses bras tout du long de l'allée:

E a labrusca errante, toda enredada,

Deixa espalhar seus ramos ao longo de toda a aleia

Não há dúvida de que Ronsard aludiu ao verso do mantuano. O que Gouveia fez aqui foi restabelecer, no nível da expressão, as palavras latinas de Virgílio, aludindo diretamente ao verso clássico que fora fonte da alusão de Ronsard e, desta forma, diminuindo a distância entre sua época e a Antiguidade, ao aproximar a expressão poética dos dois períodos. Nessa contaminatio, em que cruzou as duas versões, o lusitano não deixou de levar em conta o texto francês, como revela o emprego da palavra totam, que retoma a expressão ronsardiana tout du long e inexiste em Virgílio.

\footnotetext{
37 Tradução de Hasegawa 2012.

${ }^{38}$ Vide Hasegawa 2012, 159.

${ }^{39}$ Versão alternativa do verso: "Et la belle lambrunche, ensemble entortillée".
} 
Porém, Gouveia não se utilizaria apenas das Bucólicas. Logo no verso 5 de seu poema, por exemplo, ao falar dos dois pastores-cantores que se baterão em duelo de versos, Bellaus (referência a Bellay) e Perion (referência a Ronsard), a abertura se dá pela expressão "Fortunati ambo", que o humanista português já havia mimetizado num epigrama fúnebre a Jean D’Yberrola, e que se encontra na Eneida 9.446, referindo-se aos heróis e amigos Euríalo e Niso. Assim, Gouveia equipara os poetas e amigos Joachim du Bellay e Pierre de Ronsard aos emblemáticos guerreiros troianos, alçando-os a figuras imortais, dignas da epopeia virgiliana. O mais notável é que, neste caso, Gouveia faz isso de próprio punho, pois a frase é uma inserção feita pelo poeta lusitano, sem nenhuma correspondência na écloga de Ronsard.

Enfim, para mostrar que Gouveia não alude apenas a Virgílio, mesmo que seja para compor um poema bucólico, temos, como último exemplo, uma alusão a Ovídio. Com efeito, nos versos 126-7, o poeta lusitano constrói uma cena sem equivalente no original francês, imaginando que três reis darão presentes honoríficos ao cardeal, em retribuição pela função oracular da gruta. Essa cena simbólica, de inspiração bíblica e litúrgica católica, pode ter uma possível origem histórica no fato de que, no tratado de paz de Cateau-Cambrésis, a região conhecida como Trois-Évêchés (Três Bispados), composta pelas dioceses de Metz, Toul e Verdun, na Lorena, foi anexada à França, graças aos esforços de guerra do duque de Guise, irmão do cardeal. Aliás, a própria assinatura desse tratado, em 1559, entre os reis Filipe II da Espanha, Henrique II da França e o duque Emanuel Filiberto da Saboia, igualmente pode ter servido de fonte da passagem poética, ainda mais se levarmos em conta que a rainha Isabel I da Inglaterra também participou da assinatura da primeira parte do tratado, o que também perfaz três soberanos estrangeiros em solo francês.

Na cena poética, um dos reis ofertará uma estátua ao cardeal:

[...] ille, / Carle, tibi Pario statuam de marmore ponet

ele, Carlos, te erguerá uma estátua de mámore de Paros

O trecho alude aos versos 4.8.31-2 das Pônticas:

nec tibi de Pario statuam, Germanice, templum / marmore

E não construirei a ti, Germânico, um templo de mármore de Paros

Antes de passar para uma interpretação intertextual, cabe notar a variação que Gouveia faz ao imitar: ele transforma em substantivo (statuam, "estátua") o que era verbo em Ovídio (statuam, "erguerei").

Pensando agora no significado, por um lado, pela alusão, Gouveia promove uma identificação que lhe é cara: associa um membro da nobreza 
francesa aos Césares romanos. No caso, ele associa o cardeal de Lorena com a figura de Germânico, general de grande popularidade em Roma, filho adotivo de Tibério e, por conseguinte, neto por adoção de Augusto. Como, no poema de Ovídio, Germânico é chamado de Deus, ao qual se erguerá um templo, a assimilação de Carlos de Lorena a ele reforça a divinização do cardeal, já promovida no poema gouveiano, como vimos, no verso 75 ("semper eris nobis Deus"). Por outro lado, a alusão de Gouveia remete a um trecho do poema ovidiano em que o sulmonense explica que, por não ter dinheiro, deixará a outros a tarefa de erigir um templo a Germânico: sua forma de homenagem se limitará à composição de um poema, aquilo que um poeta pode oferecer de mais precioso. Parece-nos que, veladamente, Gouveia alude à sua condição e à condição do poema original francês, oferecido à família do cardeal: tanto Ronsard quanto Gouveia, como poetas, têm a oferecer, como dádiva mais preciosa, a sua poesia laudatória. Na versão latina feita pelo lusitano, caberá aos reis, poderosos da terra, oferecer estátuas ou coroas adornadas de diamantes. Mais uma vez, a interpretação intertextual da alusão permite encontrar significados sutilmente encobertos pelo autor humanista.

Sendo assim, podemos concluir que a intertextualidade, resultante da arte alusiva e imitação dos autores da Antiguidade, está inteiramente presente nas composições gouveianas escritas em latim, sobretudo naquelas em que o grau de elaboração e a força da imitação são mais elevados. Uma interpretação mais completa dessas obras requer não somente a identificação de prováveis alusões, mas também uma leitura mediada pela análise intertextual, a qual acaba por sugerir sentidos subjacentes a uma primeira leitura da obra neolatina. Vimos ainda como tais características se encontram também na poesia manuscrita de António de Gouveia.

Por outro lado, também foi possível notar como Gouveia manipulou com erudição e criatividade diferentes obras clássicas, mesmo quando os procedimentos da arte alusiva levam à apropriação de material antigo, num exemplo da emulação típica desse modelo imitativo de composição. Portanto, assim como no passado greco-latino, similarmente na Europa renascentista floresceu o princípio de "imitação criativa" tão bem conhecido dos Estudos Clássicos. 


\section{REFERÊNCIAS}

Austin, R. G. 1988. Aeneidos liber sextus. With comm. by R. G. Austin. Oxford: Clarendon Press.

Barchiesi, A.; Conte, G. B. 1989. "Imitazione e Arte Allusiva. Modi e funzioni dell'intertestualità". In Lo Spazio Letterario di Roma Antica. Vol. I, 81-113. Roma: Salerno Editrice.

Bem, L. A. de. 2007. O amor e a guerra no livro I d'Os Amores de Ovídio. Campinas. (Dissertação de mestrado).

Campos, H. de. 2004. Ilíada de Homero. São Paulo: Arx.

Cícero. M. T. Ciceronis Ad M. Brutum Orator. Paris: Michel de La Guierche, s.d.

Coleman, R. 2001. Vergil: Eclogues. Cambridge Greek and Latin Classics. New York: Cambridge University Press.

Conte, G. B. 1986. The Rhetoric of Imitation: genre and poetic memory in Virgil and other latin poets. Ithaca, London: Cornell University Press.

Gouveia, António de. 1539. Antonii Goueani Lusitani Epigrammaton Libri Duo. Lugdunum (Lyon): Apud Seb. Gryphium (Sébastien Gryphe).

Gouveia, António de. 1540. Antonii Goueani Epigrammata. Eiusdem Epistolae Quattuor. Lugdunum (Lyon): Apud Seb. Gryphium (Sébastien Gryphe).

Gouveia, António de. 1542. In M. T. Cic. Orationem In Vatinium Commentarius. Paris: J.-L. Tiletanus.

Gouveia, António de. 1545. Commentarius in M. T. Ciceronis Topica. Paris: Simon de Colines.

Gouveia, António de. 1552. In M. T. Ciceronis Libros De Legibus. Paris: Th. Richardus.

Gouveia, António de. 1766. Antonii Goveani Opera Iuridica, Philologica et Philosophica. Organizada por Jakob Van Vaassen. Roterdã: Apud Henricum Beman.

Hasegawa, A. P. 2012. Os limites do gênero bucólico em Vergílio. São Paulo: Humanitas.

Hinds, S. 1998. Allusion and intertext. Dynamics of appropriation in Roman poetry. Cambridge: University Press.

Ijsewijn, J.; Sacré, D. 1998. Companion to Neo-Latin studies, part II. Leuven: LUP.

Kristeller, P. O. 1963-1997. Iter Italicum. Leiden: Brill. 6 v.

Matos, L. de. 1952. Les Portugais en France au XVIe siècle: études et documents. Coimbra: UC.

Novak, M. da G. (org.). 2003. Poesia lírica latina. São Paulo: Martins Fontes.

Nunes, C. A. (trad.). 1981. Eneida. São Paulo: A Montanha.

Pasquali, G. 1968. "Arte allusiva". In Pagine stravaganti, vol.2, 275-282. Firenzi: Sansoni.

Prata, P. 2002. O caráter alusivo dos Tristes de Ovídio: uma leitura intertextual do livro I. Dissertação de mestrado defendida no Instituto de Estudos da Linguagem (IEL) da UNICAMP.

Prata, P. 2007. O caráter intertextual dos Tristes de Ovídio: uma leitura dos elementos épicos virgilianos. Tese de doutorado defendida no Instituto de Estudos da Linguagem (IEL) da UNICAMP.

Russell, D. A. 2001. "De imitatione". In Creative Imitation and Latin Literature. Cambridge: CUP. 
Serrão, J. V. 1966. António de Gouveia e o seu tempo (1510-1566), Vol. XLII. Separata do Boletim da Faculdade de Direito. Coimbra: Universidade de Coimbra.

Terêncio. 1541. Pub. Terentii Comoediae Sex. Apud Seb. Gryphium (Sébastien Gryphe). Vasconcellos, P. S. de. 2001. Efeitos intertextuais na Eneida de Virgílio. São Paulo: Humanitas.

Virgílio. 1543. Pub. Vergilii Opera. Apud Seb. Gryphium (Sébastien Gryphe). (1ª ed. 1541).

$*$

Abstract. The Portuguese humanist Antonio de Gouveia took part in the Republic of Letters of Lyon, in the 1530s, the most important period of the neo-Latin production of the French Renaissance. His work, in which the epigram predominates, is based on the imitation of classical models. In this article, we examine excerpts from three poems preserved in manuscripts, identifying and interpreting allusions to authors such as Virgil and Ovid.

Keywords. Allusion, imitatio, Humanism, epigram, Virgil, Ovid. 